\title{
The expansion of 300 CTG repeats in myotonic dystrophy transgenic mice does not induce sensory or motor neuropathy
}

\author{
E. Gantelet • R. Kraftsik • S. Delaloye • G. Gourdon • \\ T. Kuntzer • I. Barakat-Walter
}

Received: 22 December 2006 / Revised: 30 January 2007 / Accepted: 30 January 2007 / Published online: 22 February 2007

(c) Springer-Verlag 2007

\begin{abstract}
Summary Although many studies have been carried out to verify the involvement of the peripheral nervous system (PNS) in dystrophia myotonica (DM1) patients, the results remain controversial. The generation of DM1 transgenic mice displaying the human DM1 phenotype provides a useful tool to investigate the type and incidence of structural abnormalities in the PNS. In the present study, the morphological and morphometric analysis of semi-thin sections of sciatic and sural nerves, lumbar dorsal root ganglia (DRG) and lumbar spinal cords revealed that in DM1 transgenic mice carrying $300 \mathrm{CTG}$ repeats, there is no change in the number and diameter of myelinated axons compared to wild type. Only a non-significant reduction in the percentage of thin myelinated axons was detected in electron micrographs of ultra-thin sciatic nerve sections. Analysis of the number of neurons did not reveal a loss in number of either sensory neurons in the lumbar DRG or motor neurons in the lumbar spinal cord in these DM1 mice. Furthermore, in hind limb muscle sections, stained with a neurofilament antibody and $\alpha$-bungarotoxin, the intramuscular axon arborization appeared normal in DM1 mice and undistinguishable
\end{abstract}

\footnotetext{
R. Kraftsik $\cdot$ I. Barakat-Walter

Department of Cell Biology and Morphology,

University of Lausanne, Lausanne, Switzerland

E. Gantelet $\cdot$ S. Delaloye $\cdot$ T. Kuntzer $\cdot$ I. Barakat-Walter $(\square)$

Laboratory of Neurology Research,

Lausanne University Hospital (CHUV),

rue du Bugnon 46, 1011 Lausanne, Switzerland

e-mail: Ibtissam.Walter@unil.ch

G. Gourdon

INSERM U383, Hôpital Necker, Paris, France
}

from that in wild-type mice. Moreover, in DM1 mice, there was no irregularity in the structure or an increase in the endplate area. Also statistical analysis did not show an increase in endplate density or in the concentration of acetylcholine receptors. Altogether, these results suggest that 300 CTG repeats are not sufficient to induce axonopathy, demyelination or neuronopathies in this transgenic mouse model.

Keywords Myotonic dystrophy · Sensory neuropathy · DM1 transgenic mice $\cdot$ Morphometric analysis

\section{Introduction}

Myotonic dystrophy of Steinert's disease (or dystrophia myotonica, DM1) is an autosomal dominant disorder and the commonest form of muscular dystrophy in adults [16, 17]. DM1 results from the expansion of an unstable CTG repeat in the $3^{\prime}$-untranslated region of the myotonin-protein kinase (DMPK) gene on chromosome 19q, which codes for a serine/threonine protein kinase [4, 14, 29] While normal individuals have between 5-35 CTG repeats, which remain stable over generations, DM1 affected patients have 50-150 repeats in the mild form, $100-1,000$ repeats in the classical adult form and $>2,000$ repeats in the congenital form. It has been reported that the length of the expansion correlates with the severity of the clinical symptoms and age of onset [21, 40,47].

DM1, which is characterized primarily by myotonia and muscle weakness, is a multisystemic disease with a highly variable phenotype. Gastrointestinal smooth muscle abnormality is the major symptom in many patients [17, 20, 25]. However, cardiac abnormalities, 
cataracts and disturbance of endocrine function are also common complications of DM1 patients $[1,19,27$, $30,38,50]$. In addition, it has been reported that the central nervous system is also involved in DM1, particularly when onset is early. Cognitive disturbances, mental retardation, sleep disorders, behavioral changes and difficult personalities are frequently observed in congenital type DM1 adult patients [23, $34,37,49]$. While the involvement of the CNS in DM1 patients is well described, the involvement of the peripheral nervous system in the DM1 disorder is still a matter of debate and the final consequence are not completely known. The detection of sensory-motor axonal neuropathy in DM1 patients was mainly performed by electrophysiological studies, with almost no qualitative and quantitative analysis and no animal model studies. Moreover, there are no systematic studies showing the correlation between the size of the unstable CTG repeat and the type of peripheral neuropathy observed in patients. The production of transgenic mice carrying a variable number of CTG repeats offers the possibility to study the size of CTG repeats, which could induce structural changes in the peripheral nervous system and to determine the types of peripheral nerve abnormalities related to a precise length of CTG repeats.

To investigate the incidence and type of possible structural abnormalities in the peripheral nervous system, we studied transgenic mice carrying 300 CTG repeats, which display the human DM1 phenotype. We compared wild-type and DM1 mice for the absence or presence of axonal degeneration and demyelination in sciatic and sural nerves as well as neuronopathy in the dorsal root ganglia and in the spinal cord. In addition, the stability of the neuromuscular junction was investigated in the hind limb muscles.

\section{Materials and methods}

\section{Generation of DM1 transgenic mice}

Transgenic mice carrying the human genomic DM1 region with expanded repeats of approximately 300 CTG (DM1) or with 20 CTG repeats (normal) were produced and screened as previously described [44, 45]. The homozygous (DM1) transgenic mice display abnormalities in skeletal muscles, consistent with those observed in DM1 patients, whereas transgenic mice expressing 20 repeats (DM20) do not develop these changes [44, 45] and were used as internal controls.
Animal perfusion and tissue preparation

All animal procedures were conducted according to local guidelines for care and use of experimental animals.

A total of 36 mice (7-13 months) were used in this study: 12 DM1 transgenic mice, 12 internal controls (DM20 transgenic mice) and $12 \mathrm{C} 57 \mathrm{BL} / 6 \mathrm{~J}$ wild-type mice (genetic background of the DM1 transgenic mice). The mice were deeply anesthetized with pentobarbital $(75 \mathrm{mg} / \mathrm{kg})$, then transcardially perfused with $0.1 \mathrm{M}$ phosphate-buffered saline (PBS) containing $0.1 \%$ heparin and $0.1 \%$ procaine, followed by a mixture of $3 \%$ paraformaldehyde and $1.5 \%$ glutaraldehyde in $0.1 \mathrm{M}$ $\mathrm{PBS}$ at $\mathrm{pH}$ 7.4. The sciatic and sural nerves, lumbar dorsal root ganglia (DRG) as well as the lumbar spinal cord region were removed from each animal. In addition, muscles from the hind limb (gastrocnemius, triceps brachili, rectus femoris, etc.) were taken. All specimens were first post-fixed for $2 \mathrm{~h}$ at $4^{\circ} \mathrm{C}$ in the fixative, then sciatic and sural nerves, the DRG and spinal cord segments were placed in $2 \%$ osmium tetroxide in PBS for $3 \mathrm{~h}$, followed by dehydration in a series of graded ethanol and embedded in Epon. The muscles were first cryoprotected in $30 \%$ sucrose overnight, then frozen in liquid nitrogen and stored at $-80^{\circ} \mathrm{C}$.

Sciatic and sural nerve section preparation for morphological and morphometric analysis

Semi-thin transverse sections of $1 \mu \mathrm{m}$ were cut from the common trunk (before dividing into peroneal, tibial and sural branches) of sciatic nerves as well as from the proximal and distal cutaneous sural nerve stump. The sections were stained with Toluidine blue for light microscopic and morphometric analysis. For electron microscopic evaluation, ultra-thin sections $(80 \mathrm{~nm})$ were cut and stained with uranyl acetate and lead citrate and mounted onto copper grids for examination in a Zeiss EM 10C electron microscope. For more histological examination of the sural nerves, cryostat longitudinal sections of the nerves were prepared and immunostained with primary polyclonal antibody (1:200) directed against the 200-kDa neurofilament proteins (AB1982, Chemicon international).

Morphometric analysis

All counting and measurements were performed blind to experimental conditions.

- Counts of myelinated axons: The number of myelinated axons was estimated on four semi-thin nerve 
sections taken from each mouse, DM1 $(n=8)$, control mice $(n=8)$ and wild-type mice $(n=8)$, using a systematic sampling and the StereoInvestigator program (Microbrightfield Inc). With a cursor, the position of sampled fibers in more than 20 sampling boxes of $20 \times 20 \mu \mathrm{m}$ were recorded directly from the histological sections using a Zeiss Universal light microscope equipped with a motorized stage, a Sony 930XP video camera and connected to a Dell computer. The total number of axons was estimated by the StereoInvestigator program resulting from the mean local density multiplied by the surface of the nerve. More than 600 fibers per nerve were recorded.

- Measurement of myelinated axon diameter: On the same semi-thin sections, the diameter of myelinated axons was measured. Using Neurolucida software (Microbrightfield Inc), the outline of sampled myelinated fibers was digitized. The diameter of the fiber was calculated from the perimeter using the Excel program.

- Percentage of myelinated and unmyelinated axons: The percentage of myelinated and unmyelinated axons was calculated from representative electron micrographs $(5,800 \times)$ of ultra-thin nerve sections, which were captured by using electron microscopy and an image-processing program. From each nerve section, 20 images were taken from randomly selected fields (wild-type $n=4$ and DM1 transgenic mice $n=4)$ and the number of myelinated and unmyelinated axons counted using Neurolucida software (Microbrightfield Inc.). The number of myelinated or unmyelinated fibers per total number of fibers in the nerve section was estimated. On the same series of representative electron micrographs, the myelin sheath thickness was measured by sampling with line segments perpendicular to the myelin sheet contour.

Preparation of DRG and spinal cord sections and morphometric assessment

The entire ganglia or spinal cord segments from wildtype and DM1 mice were cut into serial cross-sections (1 $\mu \mathrm{m}$ thick). The sections were then stained with $0.1 \%$ Toluidine blue for $3 \mathrm{~min}$ at $80^{\circ} \mathrm{C}$, which allowed better visualization of nuclei and nucleoli profiles of the neuronal cells.

The physical disector method was used to estimate the total number of sensory and motor neurons inside the DRG and the spinal cord lumbar segment. This method is based on sampling sections, called disector pairs [46].
From each ganglion, approximately 35 disector pairs were used. The sections from the same disector pair were separated by $8 \mu \mathrm{m}$ and the separating distance between the two consecutive pairs was $30 \mu \mathrm{m}$. The estimation of the number of neurons was carried out using Neurolucida software (Microbrightfield Inc.) as described previously [43]. Briefly, in each disector pair the contour of the top section was drawn and neurons of all sizes with clear, visible nuclei were marked with an "X" symbol. The lower section was digitized and the cells with visible nuclei labeled with an "O" symbol. Then the two sections were fitted one on the other, based on their contours and landmarks. The nuclei present only in the top section (tops) of the disector pair were taken in account.

The count of the tops was extracted with the Neuroexplorer software (Microbrightfield Inc.) then divided by the volume of space bound by the outer surface of the two sections; this represents the local density of nuclei. An estimate of the local neuronal number corresponding to the local ganglion volume (volume of disector pair incremented with the volume between two consecutive disector pairs) can then be obtained by multiplying the estimated local density of nuclei by the local volume of the ganglion. The total number per ganglion can be obtained by summing up the partial numbers obtained for each disector pair. The total volume was estimated by the Cavalieri's method [15].

To estimate the number of motor neurons in the lumbar spinal cord enlargement, we used the physical disector method, adapted to the size and distribution of motor neurons inside the spinal cord. Since some motor neurons have small nuclei $(5.5 \mu \mathrm{m})$, the distance between the two sections from the same disector pair is $5 \mu \mathrm{m}$. For each mouse, 15 disector pairs were used, and two consecutive pairs were separated by $100 \mu \mathrm{m}$. Motor neurons were differentiated from glial cells on the basis of the multipolar cell shape with granular staining of the Nissl body and large pale nuclei. The estimation of the number of motor neurons inside $1.6 \mathrm{~mm}$ segments of lumbar spinal cord was made in the same manner as described for sensory neurons.

Preparation of muscle sections for neuromuscular junction analysis

Serial longitudinal cryostat sections $(20 \mu \mathrm{m})$ were prepared from muscles and mounted on microscope slides. The sections were incubated for $45 \mathrm{~min}$ in $1 \mu \mathrm{g} /$ $\mathrm{ml}$ tetramethylrhodamine-conjugated $\alpha$-bungarotoxin ( $\alpha$-BTX, Molecular probes, USA) at room temperature. The sections were then washed in PBS and 
blocked in $0.1 \%$ triton, $10 \%$ horse serum in PBS for 30 min before incubation overnight with the primary polyclonal antibody (1:200) directed against the 200-kDa neurofilament proteins (AB1982, Chemicon international). After washing with PBS, the muscle sections were incubated for $2 \mathrm{~h}$ with a 1:200 dilution of the secondary antibody conjugated to Alexa fluor 488 (Invitrogen, g \& rbA488).

The muscle sections were analyzed under fluorescent microscopy (Zeiss, Axioplan 2), and photographed using an image-acquisition program (Zeiss, Axiovision with Axiocam HRc). The images were analyzed using an image-processing program (ImageJ 1.34, NIH, USA) to measure the size and number of endplates. To avoid counting and measuring the same junction twice, every third section was analyzed. The size of each endplate was delimited by circling the area containing a region of high acetylcholine receptors (AChRs) labeling. The frequency of endplates was calculated as the number of neuromuscular junctions (NMJ) per $\mathrm{mm}^{2}$ of muscle. The intensity of AChRs labeling was also determined by measuring the average fluorescence intensity of $\alpha$-BTX at the NMJ. Images that were used for analysis were obtained under constant exposure conditions. More than 400 endplates were measured from four mice from each experimental condition. All analyses and counts were performed blinded to the animal genotype.

\section{Statistical analysis}

The estimated number of myelinated and nonmyelinated axons, the estimated total number of sensory or motor neurons and the size of the NMJ in DM1 transgenic mice were compared to the values of wild-type mice, using the hierarchical ANOVA test. $P \leq 0.05$ was considered significant. Statistical analysis was carried out using SAS software (SAS Institute Inc., Cary, NC, USA) and the general linear model procedure.

\section{Results}

Morphological and morphometric analysis of the sciatic and sural nerves

Since axonal degeneration is the most common pathologic change seen in peripheral neuropathy, we first examined the sciatic nerves in three different mouse lines: DM1 diseased mice displaying skeletal muscle abnormalities, control mice that do not develop muscle changes and wild-type mice.

Light microscopic examination of transverse semithin sections, taken from the common trunk of sciatic nerves, showed no difference in nerve structure between DM1 diseased, control and wild-type mice. In the three animal groups, the sciatic nerves consisted of four fascicules; each of them surrounded by thin perineurium containing bundles of large myelinated axons intermingled with bundles of small myelinated fibers (Fig. 1a-c). Examination of nerve sections at higher magnification confirmed the absence of changes in the sciatic nerve of DM1 mice, features of demyelination or Wallerian degeneration, and no increase in inflammatory or Schwann cell nuclei (Fig. 1d-f).

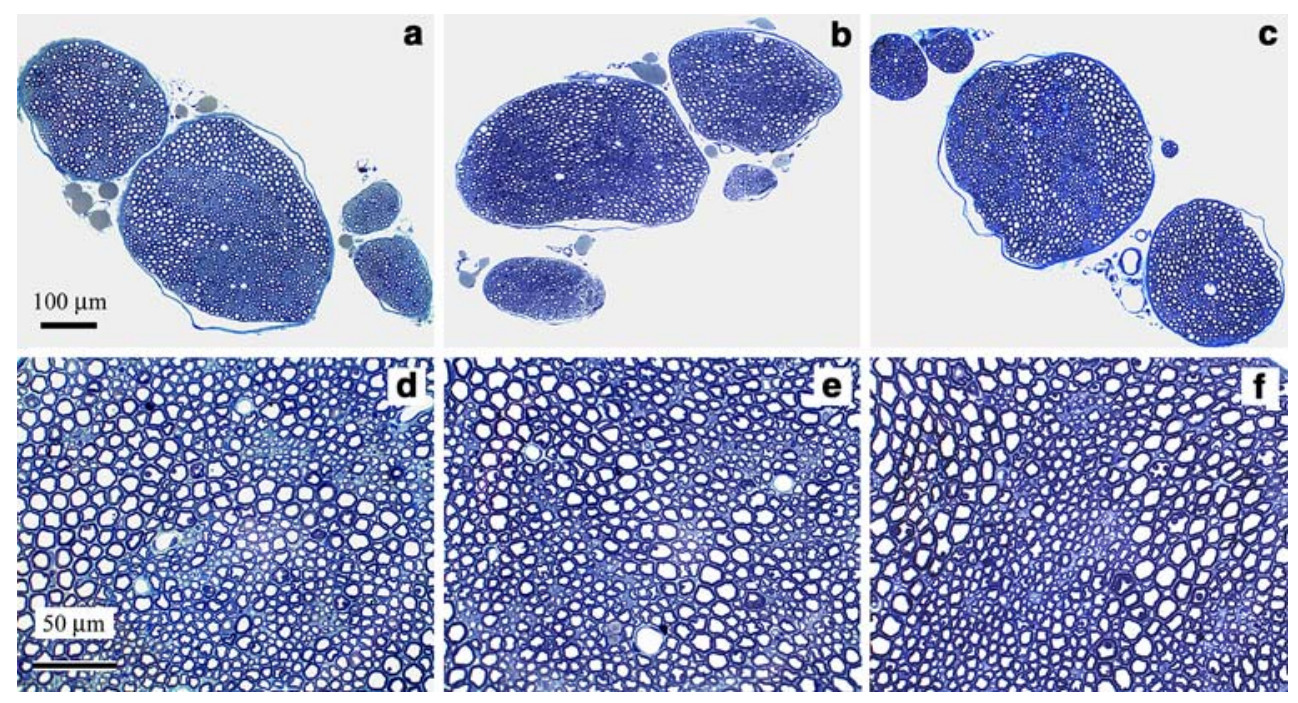

Fig. 1 Transverse semi-thin sections ( $1 \mu \mathrm{m}$ thick) from the common trunk of sciatic nerves taken from wild-type mice (a, d), control mice (b, e) and DM1 transgenic mice (c, f). The low magnification shows that there is no change in the number and size of fascicules in DM1 transgenic mice compared to controls. At high magnification, bundles of large axons intermingled with small axons can be seen in the three nerve sections; note that there is no obvious structural abnormality in DM1 transgenic mice (f) 
Counting myelinated fibers on semi-thin sections of sciatic nerves revealed no reduction in the number of myelinated fibers in DM1 mice (Fig. 2a). The statistical analysis of the counting results (16 sections, $n=8$ ) clearly showed that the mean number of myelinated axons in DM1 mice was equal to that of control and wild-type mice. Moreover, the measurement of myelinated fiber diameter on the same sections showed a comparable size-frequency distribution of axons in DM1, control and wild-type mice (Fig. 2b). In the three different mouse lines, the histogram distribution was unimodal with higher frequencies between 6 and $8 \mu \mathrm{m}$.

The electron microscopic examination of numerous ultra-thin sciatic nerve sections confirmed the absence of significant pathological changes in DM1 mice (Fig. 3). The classical signs of pathology, such as aberrant Schwann cell proliferation, Schwann cell onion bulb formation and Büngner bands were not observed in the sciatic nerve sections of DM1 mice. The presence of
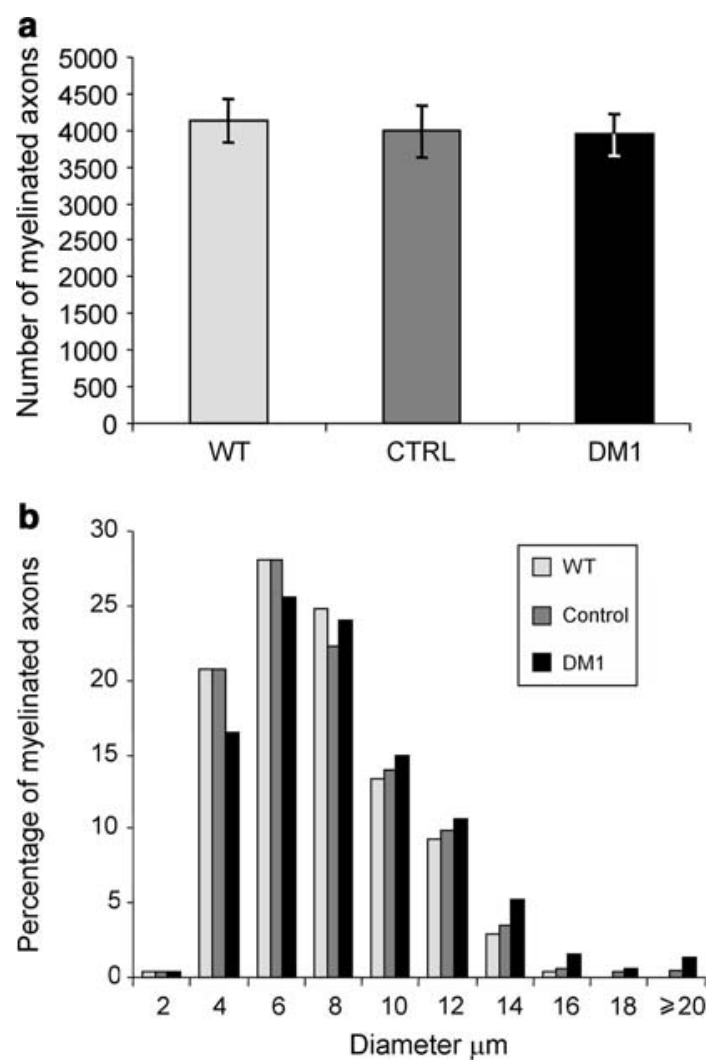

Fig. 2 Bar graph illustrating the mean number $( \pm S D)$ of myelinated axons counted on two semi-thin sciatic nerve sections per mouse taken from wild-type mice $(n=8)$, control mice $(n=8)$ and DM1 transgenic mice $(n=8)$. The statistical analysis demonstrated that there is no significant difference in the mean number of axons between DM1 mice and controls (a). Size-frequency distribution of myelinated axons' diameters, measured on the same sciatic nerve sections (b). In the three mouse lines, a comparable distribution of myelinated axons with one peak (size 6-8 $\mu \mathrm{m})$ can be observed multiple, unmyelinated axons, closely packed and enclosed by a single Schwann cell can be seen in DM1 mice as well as in wild-type mice (Fig. 3).

Although the morphological studies did not show specific pathological signs, counting of myelinated and unmyelinated fibers on ultra-thin nerve sections revealed a slight reduction in the percentage of myelinated fibers in DM1 mice. Of the 7,000 fibers counted from 80 electron micrographs of each mouse line, we found $36.2 \pm 3.22 \%$ myelinated fibers in DM1 mice and $42.6 \pm 6.3 \%$ in wild-type mice relative to the total number of fibers counted on the whole surface of the nerve section. Statistical analysis revealed that this slight reduction is not significant. Moreover, the profile of the distribution of myelin sheath thickness in DM1 mice is close to that of controls.

Likewise, histological examination of cryostat and semi-thin sections prepared from proximal and distal stumps of sural nerves showed that in either DM1 or wild-type mice, the proximal nerve segment consisted of a single fascicle, while the distal segments consisted of three or more small fascicles. Inside the sural nerve fascicles of DM1 mice, no evident axonal degeneration or other pathological signs were observed. In addition, the morphometric analysis of semi-thin sections revealed that there was no difference either in the diameter or in the mean number of myelinated fibers between DM1 $(460 \pm 35)$ and wild-type mice $(456 \pm 26)$.

Morphological and morphometric analysis of sensory and motor neurons in lumbar DRGs and spinal cord segments

The cell bodies of axons are primarily affected in neuronopathy and, therefore, we examined sensory neurons in DRGs and motor neurons in lumbar spinal cord segments.

The histological examination of DRG semi-thin sections of DM1 mice showed that sensory neurons did not display cytoplasmic features of apoptosis such as nuclear eccentricity, pyknosis, granulation, vacuolation and membrane irregularities. Neurons displayed normal histological shape, with clear Nissl bodies and large pale nuclei with one or two clear nucleoli (Fig. 4). To investigate a loss of sensory neurons, we used the physical disector method to estimate the total number of sensory neurons in lumbar DRG. As sensory neurons are unevenly distributed in the DRG, about 35 disector pairs covering the entire ganglion were used. The estimated number of sensory neurons per ganglion calculated from eight lumbar DRG clearly revealed no significant changes in the mean total number of sensory 
Fig. 3 Representative electron micrographs of thin sections of transverse nerve taken from wild-type (a, c) and from DM1 transgenic mice $(\mathbf{b}, \mathbf{d})$. In both mouse lines $(\mathbf{a}, \mathbf{b})$, numerous unmyelinated axons surrounded by a Schwann cell intermingled with normal myelinated fibers. In DM1 mice, the large myelinated axons (d) showed a diameter and myelin thickness comparable to those in wild-type mice (c)
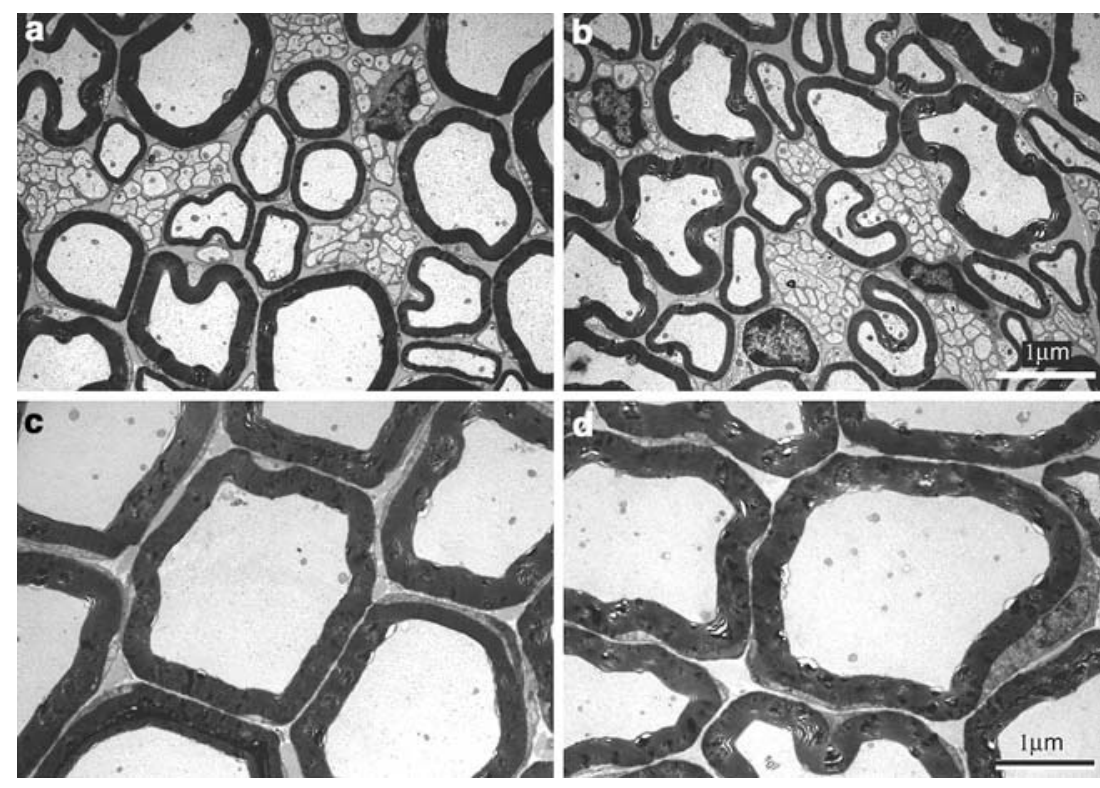

neurons per ganglion in DM1 mice $(3,942 \pm 398)$ compared to wild-type $(3,985 \pm 882)$ mice. Microscopic examination at low magnification $(2.5 \times)$ of lumbar spinal cord semi-thin sections showed no detectable changes in the aspect and size of white and gray matter in DM1 mice compared to wild-type mice (Fig. 5). At higher magnification $(10 \times)$, small and large motor neurons in the anterior horn of the DM1 spinal cords appeared normal and free from degeneration features (Fig. 5d). The estimation of the number of these neurons by the physical disector method revealed that the mean number of motor neurons in a $1.6 \mathrm{~mm}$ lumbar spinal cord segment was identical in DM1 $(4,363 \pm$ $1,331)$ and in wild-type mice $(4,174 \pm 1,346)$.

Morphological and morphometric analysis of neuromuscular junctions

Histological examination of hind limb muscle sections showed that AChR clusters were observed in all the examined sections of DM1 and wild-type mice. In both mouse lines, some muscle sections showed fascicules of neurofilament immunopositive fibers, oriented parallel to the muscle fibers. The axons give rise to some branches and each branch innervates muscle fibers at a single motor endplate (Fig. 6). Therefore, the axon arborization is normal in DM1 transgenic mice as observed in control mice.

Examination of muscle sections at higher magnification demonstrated that in both DM1 mice or wild-type mice, most of the endplates were typical with AChRs concentrated in a pretzel-like pattern. Other small and simple NMJ shapes were also observed in the two mouse lines (Fig. 6). Thus, the NMJ observed in DM1 transgenic mice were similar in shape and complexity to those in control mice. The endplate size frequency distribution (Fig. 7a) and the mean endplate area in DM1 mice was comparable to those in wild-type mice. In fact, the mean major endplate diameter (Feret's diameter) in DM1 is $35 \pm 2.3 \mu \mathrm{m}$ and in controls $37 \pm 2.3 \mu \mathrm{m}$. The estimation of the mean number of NMJ per $\mathrm{mm}^{2}$ of skeletal muscle (density of NMJ) and the statistical analysis showed that there was no significant difference between DM1 and wild-type mice (Fig. 7b). Also, there was no difference between wildtype and DM1 mice in the intensity of AChR concentration, in the post synaptic membrane, quantitated by measuring the mean fluorescence intensity of $\alpha$-BTX in the endplate (Fig. 7c).

\section{Discussion}

The present study provides evidence that DM1 mice carrying the 300 CTG repeat failed to show structural abnormalities in the peripheral nervous system. The morphological and morphometric analysis of the sciatic and sural nerves, dorsal root ganglia and spinal cord in DM1 mice clearly revealed a lack of axonal degeneration, no significant demyelination and no sensory or motor neuronopathy. In addition, the histological examination and the statistical analysis of hind limb muscles from DM1 mice ruled out abnormalities of intramuscular nerve endings and of neuromuscular junction structures. These results suggest that the small length (300) of the CTG repeat in DM1 mice is not sufficient to induce peripheral sensory-motor neuropathy. 

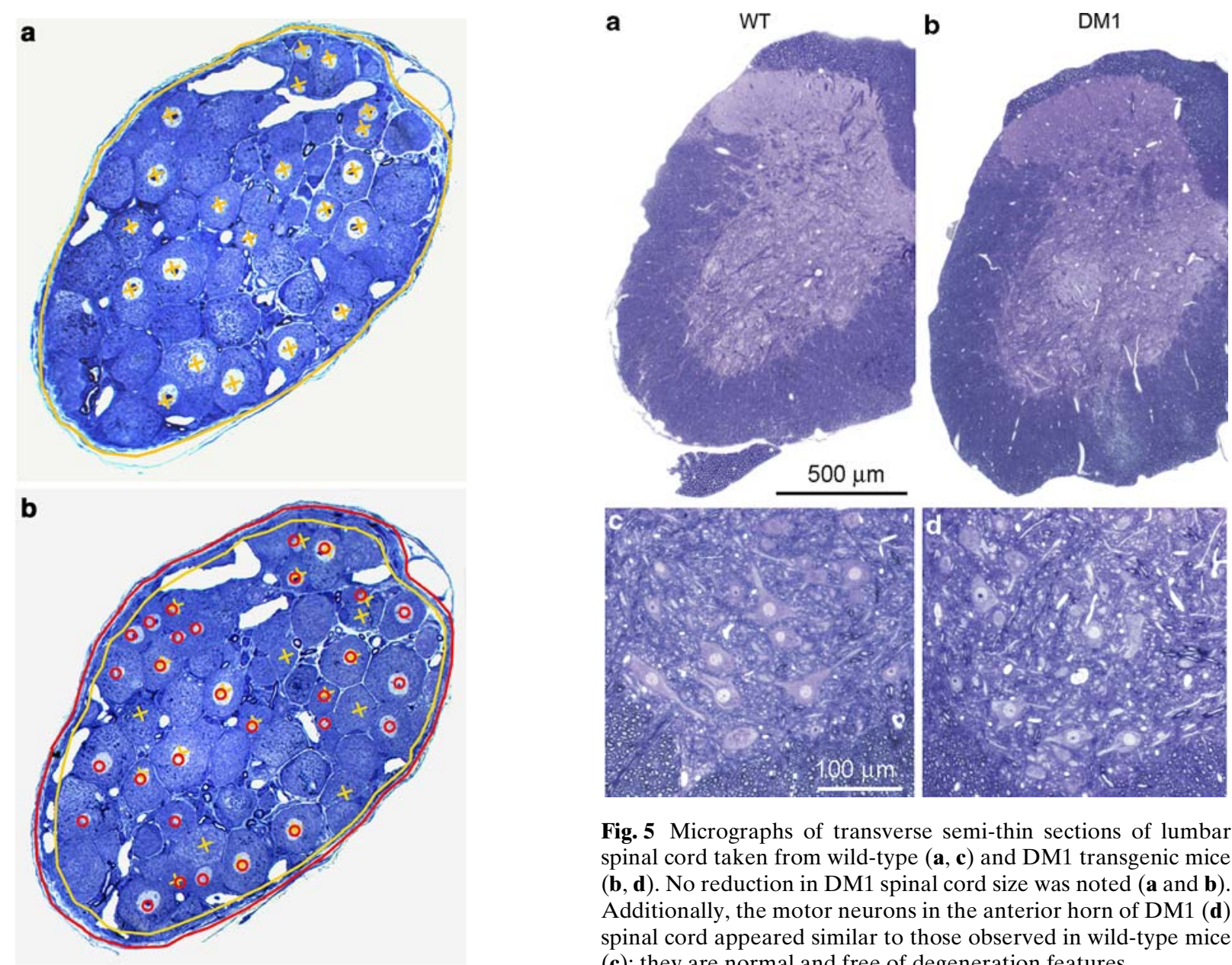

Fig. 5 Micrographs of transverse semi-thin sections of lumbar spinal cord taken from wild-type (a, c) and DM1 transgenic mice $(\mathbf{b}, \mathbf{d})$. No reduction in DM1 spinal cord size was noted (a and b). Additionally, the motor neurons in the anterior horn of DM1 (d) spinal cord appeared similar to those observed in wild-type mice (c); they are normal and free of degeneration features

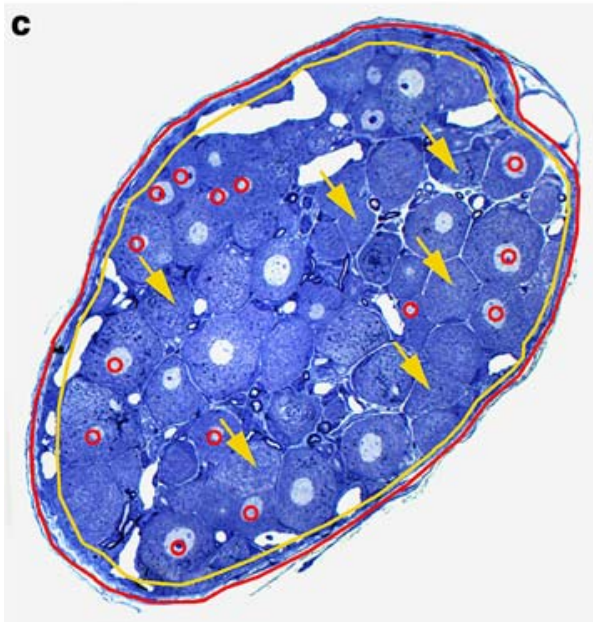

Although the involvement of the brain and other organs in DM1 is well documented, a doubt still exists about the genuine involvement of the peripheral nervous system in DM1. Since 1950, conflicting results concerning the involvement of the peripheral nervous system in DM1 have been reported. While both mild and severe impairment of nerve conduction has been reported in DM1 patients by several authors $[3,5,10$, $22,24,33,42,51,54]$, others denied the presence of peripheral neuropathy in DM1 patients $[6,12,39]$ or provided evidence that there was no relationship between the degree of neurogenic involvement and the severity of muscular atrophy $[11,32,35,36,53]$. Moreover, the histological and morphometric analysis of

Fig. 4 Micrographs of two DRG sections from the same disector pair of a wild-type mice: a top section, $\mathbf{b}$ neurolucida drawing of the two sections superimposed on the micrograph of the bottom section and $\mathbf{c}$ bottom section showing the retained profiles. All nuclei that appeared on the top section are labeled with $X$ symbol, the nuclei that appeared in the bottom section are labeled with $O$ symbol and the nuclei that appeared in both sections are labeled with both $X$ and $O$ symbols. The nuclei that appear only in the top section and not in the bottom section (tops) are indicated by arrows nerve biopsies are scanty in human studies and have provided contrasting results. While no changes in the peripheral nerves and in the number of spinal cord motor neurons were reported $[9,39]$, abnormalities in distal nerve fibers and intramuscular bundles are described by others $[3,7,8,28]$. It is necessary to emphasize that these studies, which have confirmed or denied association of peripheral neuropathy to DM1 

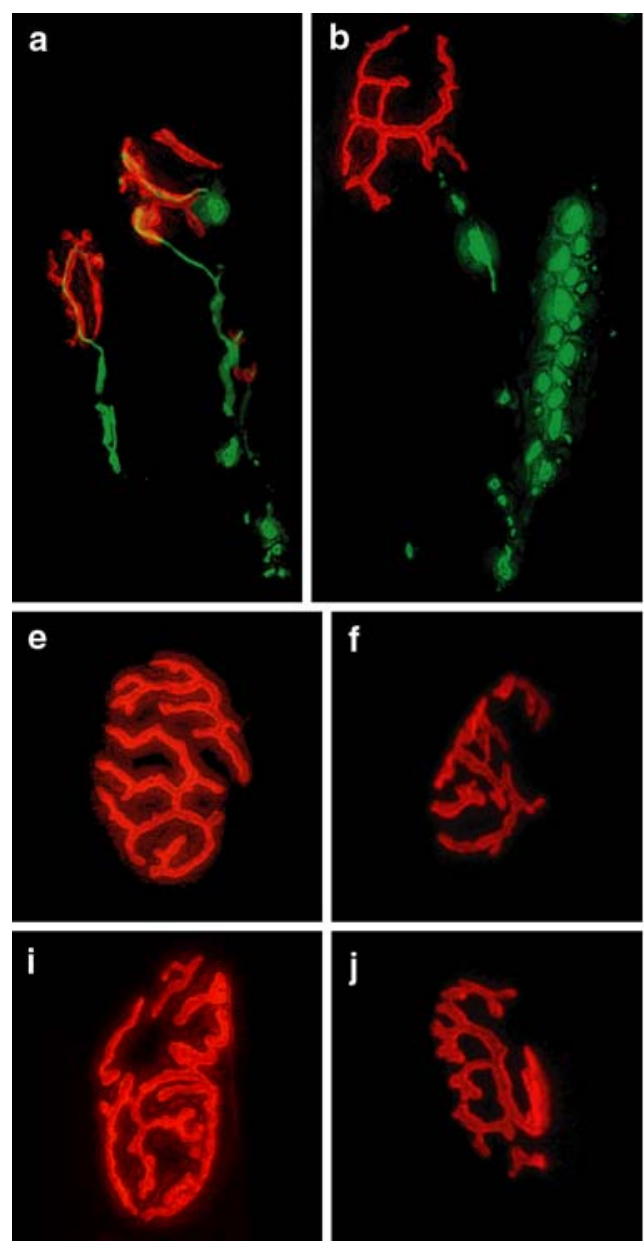

Fig. 6 Skeletal muscle sections stained with neurofilament antibody (green) and rhodamine $\alpha$-BTX (red). Note that either in wild-type $(\mathbf{a}, \mathbf{b})$ or in DM1 (c, d) mice, each endplate is innervated

disease, did not provide data concerning the relationship between the length of the CTG repeat and the presence or absence of neuropathy in patients. Therefore, an association between neuropathy and DM1 remains open, and the possible types, frequencies and extents of peripheral nerve abnormalities in DM1 could be studied and clarified in the various transgenic mice models carrying defined lengths of CTG repeats.

The creation of animal models for human genetic diseases allows the study of structural changes in several tissues, which cannot usually be performed directly on patients [55]. Among the several animal models created for DM1, the transgenic mice generated by Seznec et al. [44, 45] are extremely valuable. Numerous histological, molecular and electromyographic analyses [44, 45] show that transgenic mice, which carry a defined CTG expansion as in the human DM1 context ( $>45 \mathrm{~kb}$ ) and produce the abnormal DMPK mRNA with at least 300 CUG repeats, display DM1 phenotypic abnormalities: i.e., (1) growth
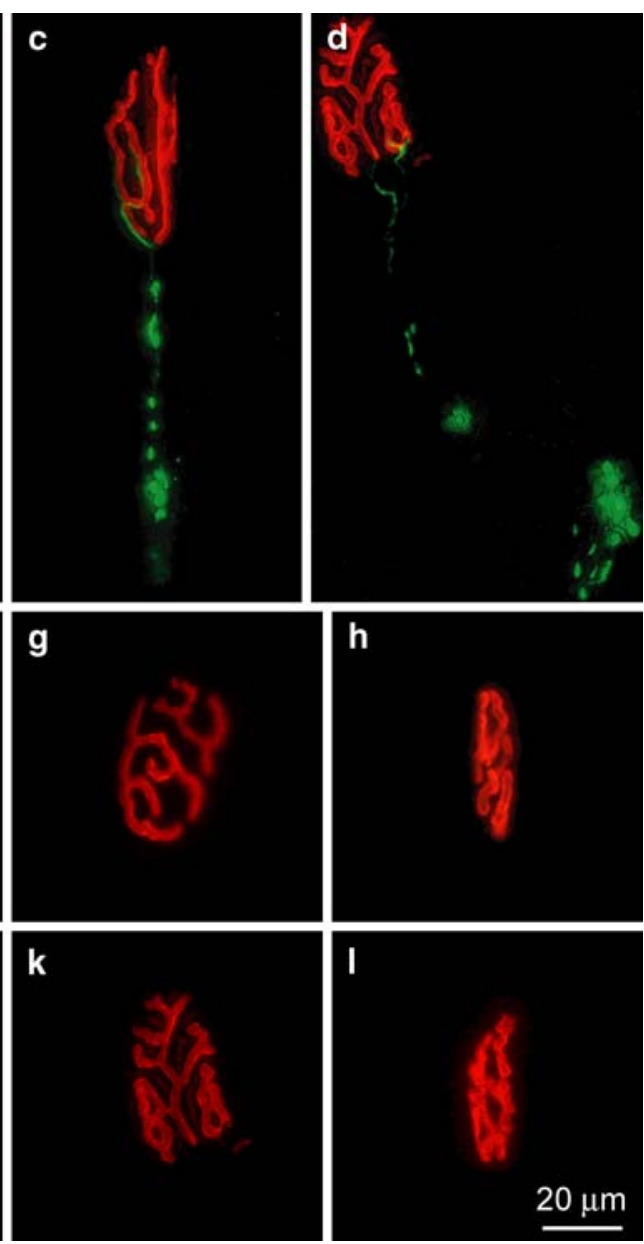

by a branch of axon. Representative images of different shapes of NMJ observed in wild-type (e-h) and DM1 (i-l) mice

retardation and abnormal posture, (2) crossed teeth and anal prolapse, (3) heterogeneity in the diameter of muscle fibers, fibrosis and infiltration of fatty tissue, as well as large numbers of centro-nucleated muscle fibers in the soleus and sternomastoid muscles, (4) atrophy of the slow muscle fibers and an increase in the number of these fibers, (5) expression of the human DMPK gene in transgenic mice tissues and (6) detection of myotonic activity in the muscles of the fore and hind legs. Thus, these DM1 transgenic mice carrying a defined number of CTG repeats are a useful tool to detect whether the peripheral nervous system also displays structural and morphometric abnormalities.

Since axonal degeneration, demyelination and neuronopathy are the three major pathological processes that affect the peripheral nervous system [31], our efforts focused on the detection of these processes in sciatic and sural nerves, DRG and spinal cords from wild-type and DM1 mice. The results of morphological and morphometric analysis of semi-thin nerve sections 

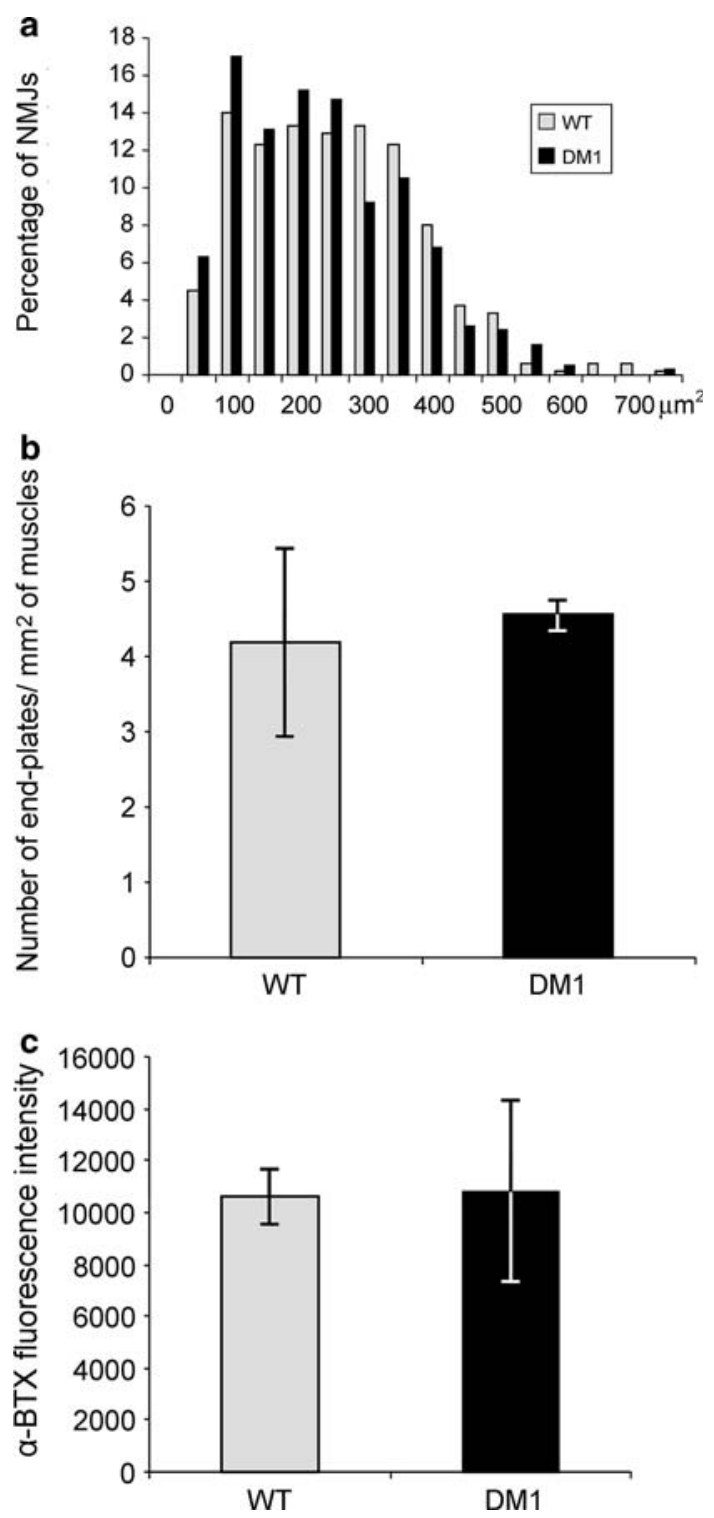

Fig. 7 On longitudinal muscle sections stained with $\alpha$-BTX, the area and the intensity of labeling of 400 endplates (from each mouse group) were measured. Size-frequency distribution histograms of endplate areas (a). Note that in DM1 mice, the endplate area is shifted slightly, but not significantly towards smaller values. Histogram representing the mean number of the endplates per $\mathrm{mm}^{2}$ of skeletal muscle (b). The total number of NMJ was divided by the whole muscle section surface. No significant difference between DM1 and wild-type mice can be observed. Histogram representing the mean $\alpha$-BTX fluorescence intensity per area of endplate (c). The fluorescence intensity, which reflects the concentration of AchRs on the post synaptic membrane is identical in DM1 and in wild-type mice

showed that in DM1 mice, there is no loss in the number of myelinated fibers and no significant change in their diameter, indicating no demyelination or degeneration of large myelinated fibers in sciatic or in sural nerves. Only a slight, but no significant reduction was found in the percentage of thin myelinated fibers following analysis of sciatic nerve electron micrographs. This slight reduction may not represent the classical neuropathy observed in DM1 patients, which affects preferentially large myelinated axons described by some authors $[10,54]$. The estimation of the number of neurons by the physical disector method revealed no changes in the number of surviving sensory neurons or motor neurons in DM1 mice compared to the control. This result rules out a possible association of neuronopathies with DM1. Since changes of terminal axons and endplates have been detected in biopsies of DM1 muscles in patients $([2,3,7-9,28]$, we specifically analyzed the muscles of wild-type and DM1 mice, and again systematic histological and morphometric analysis of hind limb muscle sections did not show striking axonal sprouting or changes in the size or number of motor endplates in DM1 mice. This result excludes a defect in motor innervation of skeletal muscle and a loss of motor units. Our findings therefore rule out the presence of the three major pathological processes in DM1 transgenic mice carrying 300 CTG repeats. The fact that these DM1 transgenic mice display human DM1 phenotypes, but not peripheral neuropathies, suggests that the expansion of 300 CTG repeats may not be sufficient to induce clear peripheral sensory-motor disorders. Another explanation is that there is no association between peripheral neuropathy and DM1 disease. The first hypothesis seems to us more probable because it is in agreement with clinical data, which demonstrate that the size of the CTG repeat region, which increases from generation to generation, is correlated with the clinical severity of the disease [18, 47]. Moreover, this hypothesis can also be supported by findings of several authors who reported that the severity of the peripheral neuropathy associated with DM1 appears to depend largely on the patient's age, the stage of the disorder as well as the time of progression [26, 41, 52, 54]. It has also been shown that the involvement of the CNS (cognitive impairment, somnolence, apathy, personality, depression, etc.) in DM1 is more marked in individuals with large expansions, greater than 1,000 CTG repeats $[13,47,48]$. Taking these data into consideration, we believe that $300 \mathrm{CTG}$ repeats are not sufficient to induce sensory-motor neuropathy in DM1 transgenic mice. In addition, this hypothesis could explain why in a same group of patients, some show a severe slowing of motor and sensory conduction velocities, others mild abnormalities, and normal sensory conduction in the other patients [10, 26, 33]. At present, the efforts of the group of Dr G. Gourdon focus on the production of DM1 transgenic mice carrying larger CTG repeats $(700-1,000)$. We plan to use these transgenic mice in the near future to confirm our hypothesis. 


\section{Conclusion}

Since the association of peripheral neuropathy with DM1 is still a matter of debate, we studied DM1 transgenic mice carrying $300 \mathrm{CTG}$ repeats to assess the type and the incidence of structural alterations in sciatic and sural nerves, dorsal root ganglia and spinal cord. The morphological and morphometric analysis rule out the presence of axonal degeneration, demyelination of large axons and neuronopathy in these DM1 mice. Our results suggest that 300 CTG repeats are not sufficient to induce peripheral sensory-motor neuropathy in this animal model.

Acknowledgments The authors express their gratitude to Drs. M. Price and G. Grenningloh for their critical reading of the manuscript, Prof. S. Fakan for the electron microscopy facility and E. Bernardi for the artwork. This work was supported by grants from the Swiss National Science Foundation $\mathrm{N}^{\circ} 3100$ 102175 and Novartis foundation 2004.

\section{References}

1. Abe T, Sato M, Kuboki J, Kano T, Tamai M (1999) Lens epithelial changes and mutated gene expression in patients with myotonic dystrophy. Br J Ophthalmol 83:452-457

2. Allen DE, Johnson AG, Woolf AL (1969) The intramuscular nerve endings in dystrophia myotonica-a biopsy study by vital staining and electron microscopy. J Anat 105:1-26

3. Borenstein S, Noel P, Jacquy J, Flamentdurand J (1977) Myotonic dystrophy with nerve hypertrophy. Report of a case with electrophysiological and ultrastructural study of the sural nerve. J Neurol Sci 34:87-99

4. Brook JD, McCurrach ME, Harley HG, Buckler AJ, Church D, Aburatani H, Hunter K, Stanton VP, Thirion JP, Hudson T (1992) Molecular basis of myotonic dystrophy: expansion of a trinucleotide (CTG) repeat at the $3^{\prime}$ end of a transcript encoding a protein kinase family member. Cell 69:385

5. Caccia MR, Negri S, Parvis VP (1972) Myotonic dystrophy with neural involvement. J Neurol Sci 16:253-269

6. Caruso G, Ferrannini E (1976) Conventional electromyography in myotonic dystrophy. Riv Patol Nerv Ment 97:263-276

7. Coers C (1955) Histological and histo-chemical study of the neuromuscular junction in myotonic syndromes. Acta Neurol Psychiatr Belg 55:17-22

8. Coers C (1955) Normal and pathological structural variations of the myoneural junction. Acta Neurol Psychiatr Belg $55: 741-866$

9. Coers C, Chou SM (1981) The pathological anatomy of the neuromuscular junction. In: Sir John Walton (ed) Disorders of voluntary muscle. Churchill Livingstone, Edinburgh, pp 210-240

10. Cros D, Harnden P, Pouget J, Pellissier JF, Gastaut JL, Serratrice G (1988) Peripheral neuropathy in myotonic dystrophy: a nerve biopsy study. Ann Neurol 23:470-476

11. Cruz MA, Ferrer MT, Perez Conde MC (1984) Electrophysiological studies in myotonic dystrophy. 1: potential motor unit parameters and conduction velocity of the motor and sensory peripheral nerve fibres. Electromyogr Clin Neurophysiol 24:523-535
12. D'Alessandro G, Bottacchi E, Gambaro P, Camerlingo M, Mamoli A (1987) Evoked potentials in 3 cases of dystrophia myotonica with neuropathic variant. Riv Neurol 57:269-273

13. Damian MS, Bachmann G, Koch MC, Schilling G, Stoppler S, Dorndorf W (1994) Brain disease and molecular analysis in myotonic dystrophy. Neuroreport 5:2549-2552

14. Fu YH, Pizzuti A, Fenwick RG Jr, King J, Rajnarayan S, Dunne PW, Dubel J, Nasser GA, Ashizawa T, de Jong P, (1992) An unstable triplet repeat in a gene related to myotonic muscular dystrophy. Science 255:1256-1258

15. Gundersen HJ, Bendtsen TF, Korbo L, Marcussen N, Moller A, Nielsen K, Nyengaard JR, Pakkenberg B, Sorensen FB, Vesterby A. (1988) Some new, simple and efficient stereological methods and their use in pathological research and diagnosis. APMIS 96:379-394

16. Harper PS (1989) Gene mapping and the muscular dystrophies. Prog Clin Biol Res 306:29-49

17. Harper PS (ed) (2001) Myotonic dystrophy. WB Saunders, Philadelphia

18. Harper PS, Harley HG, Reardon W, Shaw DJ (1992) Anticipation in myotonic dystrophy: new light on an old problem. Am J Hum Genet 51:10-16

19. Hiromasa S, Ikeda T, Kubota K, Hattori N, Coto H, Maldonado C, Kupersmith J (1988) Ventricular tachycardia and sudden death in myotonic dystrophy. Am Heart J 115:914915

20. Horowitz M, Maddox A, Maddern GJ, Wishart J, Collins PJ, Shearman DJ (1987) Gastric and esophageal emptying in dystrophia myotonica. Effect of metoclopramide. Gastroenterology 92:570-577

21. Hunter A, Tsilfidis C, Mettler G, Jacob P, Mahadevan M, Surh L, Korneluk R (1992) The correlation of age of onset with CTG trinucleotide repeat amplification in myotonic dystrophy. J Med Genet 29:774-779

22. Jamal GA, Weir AI, Hansen S, Ballantyne JP (1986) Myotonic dystrophy. A reassessment by conventional and more recently introduced neurophysiological techniques. Brain 109(Pt 6):1279-1296

23. Kiuchi A, Otsuka N, Namba Y, Nakano I, Tomonaga M (1991) Presenile appearance of abundant Alzheimer's neurofibrillary tangles without senile plaques in the brain in myotonic dystrophy. Acta Neuropathol (Berl) 82:1-5

24. Krishnan AV, Kiernan MC (2006) Axonal function and activity-dependent excitability changes in myotonic dystrophy. Muscle Nerve 33:627-636

25. Kusunoki M, Hatada T, Ikeuchi H, Okamoto T, Sakanoue Y, Utsunomiya J (1992) Gastric volvulus complicating myotonic dystrophy. Hepatogastroenterology 39:586-588

26. Logullo F, Censori B, Danni M, Del Pesce M, Di Bella P, Provinciali L (1992) Peripheral neuropathy in myotonic dystrophy: electrophysiological and clinical features. Electromyogr Clin Neurophysiol 32:515-520

27. Lou XY, Nishi Y, Haji M, Antoku Y, Tanaka S, Ikuyama S, Yanase T, Takayanagi R, Nawata H (1994) Reserved Sertoli cell function in the hypogonadic male patients with myotonic dystrophy. Fukuoka Igaku Zasshi 85:168-174

28. Macdermot V (1961) The histology of the neuromuscular junction in dystrophia myotonica. Brain 84:75-84

29. Mahadevan M, Tsilfidis C, Sabourin L, Shutler G, Amemiya C, Jansen G, Neville C, Narang M, Barcelo J, O'Hoy K (1992) Myotonic dystrophy mutation: an unstable CTG repeat in the $3^{\prime}$ untranslated region of the gene. Science 255:1253-1255

30. Mastrogiacoma F, Bettendorff L, Grisar T, Kish SJ (1996) Brain thiamine, its phosphate esters, and its metabolizing enzymes in Alzheimer's disease. Ann Neurol 39:585-591 
31. McLeod JG (1995) Investigation of peripheral neuropathy. J Neurol Neurosurg Psychiatry 58:274-283

32. Messina C, Tonali P, Scoppetta C (1976) Electrophysiological observations in dystrophia myotonica and distal myopathy. Riv Neurol 46:542-552

33. Mondelli M, Rossi A, Malandrini A, Della PP, Guzaai GC (1993) Axonal motor and sensory neuropathy in myotonic dystrophy. Acta Neurol Scand 88:141-148

34. Ono S, Takahashi K, Jinnai K, Kanda F, Fukuoka Y, Kurisaki H, Mitake S, Inagaki T, Yamano T, Nagao K (1998) Loss of serotonin-containing neurons in the raphe of patients with myotonic dystrophy: a quantitative immunohistochemical study and relation to hypersomnia. Neurology 50:535-538

35. Panayiotopoulos CP, Scarpalezos S (1977) Dystrophia myotonica. A model of combined neural and myopathic muscle atrophy. J Neurol Sci 31:261-268

36. Paramesh K, Smith BH, Kalyanaraman K (1975) Early onset myotonic dystrophy in association with polyneuropathy. J Neurol Neurosurg Psychiatry 38:1136-1139

37. Park JD, Radtke RA (1995) Hypersomnolence in myotonic dystrophy: demonstration of sleep onset REM sleep. J Neurol Neurosurg Psychiatry 58:512-513

38. Phillips MF, Harper PS (1997) Cardiac disease in myotonic dystrophy. Cardiovasc Res 33:13-22

39. Pollock M, Dyck PJ (1976) Peripheral nerve morphometry in myotonic dystrophy. Arch Neurol 33:33-39

40. Redman JB, Fenwick RG Jr, Fu YH, Pizzuti A, Caskey CT (1993) Relationship between parental trinucleotide GCT repeat length and severity of myotonic dystrophy in offspring. JAMA 269:1960-1965

41. Roohi F, List T, Lovelace RE (1981) Slow motor nerve conduction in myotonic dystrophy. Electromyogr Clin Neurophysiol 21:97-105

42. Rossi B, Sartucci F, Stefanini A, Pucci G, Bianchi F (1983) Measurement of motor conduction velocity with Hopf's technique in myotonic dystrophy. J Neurol Neurosurg Psychiatry 46:93-95

43. Schenker M, Kraftsik R, Glauser L, Kuntzer T, Bogousslavsky J, Barakat-Walter I (2003) Thyroid hormone reduces the loss of axotomized sensory neurons in dorsal root ganglia after sciatic nerve transection in adult rat. Exp Neurol 184:225-236

44. Seznec H, Agbulut O, Sergeant N, Savouret C, Ghestem A, Tabti N, Willer JC, Ourth L, Duros C, Brisson E, Fouquet C,
Butler-Browne G, Delacourte A, Junien C, Gourdon G (2001) Mice transgenic for the human myotonic dystrophy region with expanded CTG repeats display muscular and brain abnormalities. Hum Mol Genet 10:2717-2726

45. Seznec H, Lia-Baldini AS, Duros C, Fouquet C, Lacroix C, Hofmann-Radvanyi H, Junien C, Gourdon G (2000) Transgenic mice carrying large human genomic sequences with expanded CTG repeat mimic closely the DM CTG repeat intergenerational and somatic instability. Hum Mol Genet 9:1185-1194

46. Sterio DC (1984) The unbiased estimation of number and sizes of arbitrary particles using the disector. J Microsc 134(Pt 2):127-136

47. Tsilfidis C, MacKenzie AE, Mettler G, Barcelo J, Korneluk RG (1992) Correlation between CTG trinucleotide repeat length and frequency of severe congenital myotonic dystrophy. Nat Genet 1:192-195

48. Turnpenny P, Clark C, Kelly K (1994) Intelligence quotient profile in myotonic dystrophy, intergenerational deficit, and correlation with CTG amplification. J Med Genet 31:300-305

49. van Spaendonck KP, Ter Bruggen JP, Weyn Banningh EW, Maassen BA, Van de Biezenbos JB, Gabreels FJ (1995) Cognitive function in early adult and adult onset myotonic dystrophy. Acta Neurol Scand 91:456-461

50. Vazquez JA, Pinies JA, Martul P, De los RA, Gatzambide S, Busturia MA (1990) Hypothalamic-pituitary-testicular function in 70 patients with myotonic dystrophy. $\mathrm{J}$ Endocrinol Invest 13:375-379

51. Vital C, Vallat JM, Gruyer G, Coquet M, Rivel J (1980) Anatomo-clinical study of muscular sarcodosis. Ultrastructural examination of two biopsies (author's transl). Arch Anat $\mathrm{Cy}$ tol Pathol 28:214-221

52. von Giesen HJ, Stoll G, Koch MC, Beneck R (1994) Mixed axonal-demyelinating polyneuropathy as predominant manifestation of myotonic dystrophy. Muscle Nerve 17:701-703

53. Walton JN, Irving D, Tomlinson BE (1977) Spinal cord limb motor neurons in dystrophia myotonica. J Neurol Sci 34:199_ 211

54. Wang JF, Schroder JM (2000) Comparative morphometric evaluation of peripheral nerves and muscle fibers in myotonic dystrophy. Acta Neuropathol (Berl) 99:39-47

55. Wynshaw-Boris A (1996) Model mice and human disease. Nat Genet 13:259-260 